\title{
Clinical audit in the Pediatric primary care office setting: a tool for improvement of overweight prevention in preschool age.
}

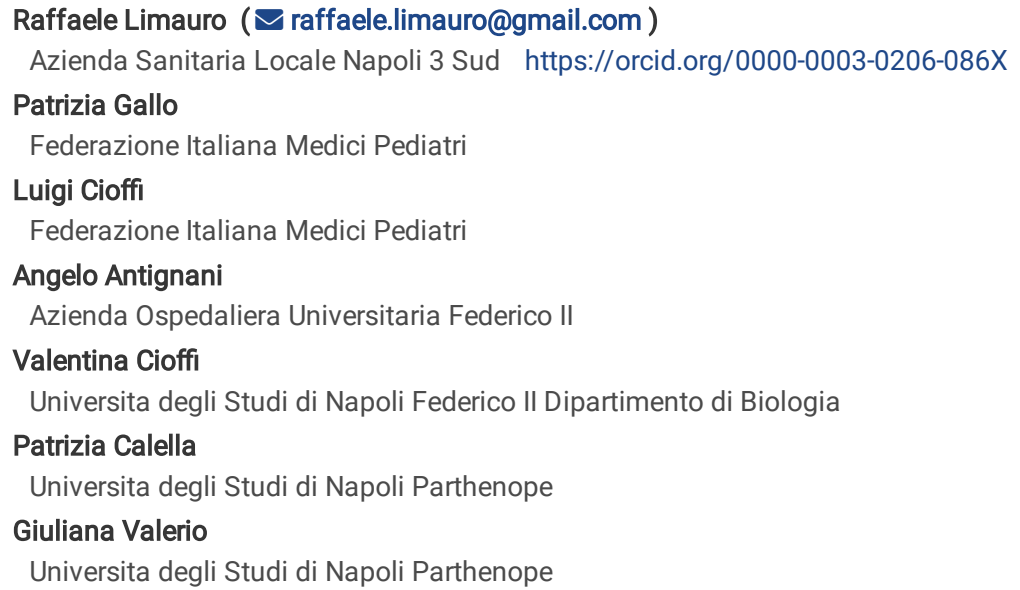

Version of Record: A version of this preprint was published at BMC Pediatrics on April 14th, 2020. See the published version at https://doi.org/10.1186/s12887-020-02076-y. 


\section{Abstract}

Background: Clinical audit is a process by which physicians or other health care professionals perform a regular and systematic review of their clinical practice and amend it, when necessary. An internal audit allows to review the activities carried out by professionals, in order to assess the appropriateness, effectiveness, efficiency and safety of the services provided. Aim of this study was to apply the process of clinical audit to the obesity/overweight care in young children. After the correction of the nutritional errors that were considered potentially responsible for the excess weight gain, the effect of the changes of dietary advices on the frequency of overweight/obesity was assessed in a cohort of children aged 24-36 months.

Methods: Three Italian primary care pediatricians have applied the audit strategy by recognizing the high prevalence of overweight and obesity in the entire cohort of children born in 2005, 2006 and 2007 (Pre-Audit group, age 24-36 months old) under their care. By reviewing their clinical practice, they changed the protocol of weaning and feeding up to 36 months, mainly reducing the protein intake. The change involved the cohorts of children born in the years 2010 , 2011 and 2012 (Post-Audit group).

Results: Changes in children's diet yielded a reduction of the frequency of overweight and obesity between 24 and 36 months of life in the Post-Audit group.

Conclusion: Clinical audit can be an effective tool in identifying inaccuracies in medical procedures and helpful in revising them.

\section{Background}

Clinical audit is a process by which physicians, nurses or other health care professionals perform a regular and systematic review of their clinical practice and amend it, when necessary [1]. This revision process, based on established criteria, has the main purpose to evaluate the efficacy, effectiveness, and safety of medical care. The final report provides indications aimed to improve medical care [2]. The availability of electronic medical records represents an important source of data for audits.

An audit process that investigates the possible nutritional errors responsible of overweight and obesity in young children may be an opportunity for the appraisal of patient care, implementing specific educational measures considered for improvement. Indeed, childhood obesity represents one of the most important health issue worldwide. Specifically, the prevalence of overweight and obesity in the South of Italy (Campania region) is the highest in the country, as assessed by the Nutritional Surveillance system "Okkio alla Salute". According to the last estimate in the 2016 [3] the prevalence of overweight and obesity in children living in the Campania region amounted to $44.1 \%$ (26.2\% overweight, $17.9 \%$ obesity). In early life, nutritional factors play a greater role on weight gain than other environmental factors, such as physical activity, and are associated to adiposity increase from the prenatal age through the first 36 months of life [4]. Therefore, it is indispensable that pediatricians carefully revise their recommendations about complementary feeding and diet in the first 36 months of life. In particular, beyond sugar overconsumption [5], the excessive protein intake, especially of lacto-proteins, has been identified as a risk factor for the premature development of obesity [6-8] leading to early adiposity rebound [9-11]. On the other side, a correct protein intake may be protective [12].

Since translating nutritional guidelines into clinical practice often needs a long processing time to ensure the optimal care of children, audit may be used to improve the quality of care leading to small but potentially important enhancements in the medical care [13]. As all the primary care pediatricians in Italy are provided with a medical software to store the demographic and clinical data of their child population, the revision of their clinical practice is facilitated.

Our study was conducted in the Pediatric primary care office setting in Campania region and was aimed at assessing the impact of the clinical audit on the evaluation of the possible nutritional errors underpinning the excess weight and measure the effect of the changes of dietary advices on the frequency of overweight/obesity in children aged $24-36$ months.

\section{Methods}

The audit was prompted in 2009 when three primary care pediatricians working in Naples (Campania region) measured the frequency of overweight and obesity in their child population from their electronic databases and realized that nearly one third of the entire cohort of children born in 2005,2006 and 2007 (age 24-36 months old) under their care (Pre-Audit Group) was overweight or obese (Table 1).

\section{[Insert Table 1]}

Possible nutritional causes were hypothesized on the basis of the literature. Complementary diet and diet recommendations up to 36 months of life were discussed and the possible errors were identified (Table 2) (Identification of the problem).

[Insert Table 2]

In order to reduce the frequency of overweight/obesity (Goal), pediatricians drafted a protocol of weaning and feeding up until the age of 36 months, which was mainly focused on the reduction of protein intake [14] (Table 2). The updated recommendations were addressed to the cohorts of children born in the years 2010-2011-2012 (Post-Audit Group) (Action), starting at the time of weaning (around the $6^{\text {th }}$ month of life), and progressively continuing up to age of 36 months. The feeding practices of parents was assessed at the scheduled visits; the assessment of overweight/obesity was carried out at 24-36 months of life (Monitoring). The study was approved by the Ethical Committee "Campania Sud" of the ASL Napoli 3 Sud and was performed in accordance with the 1975 Declaration of Helsinki revised in 1983. To ensure data protection and confidentiality, data were de-identified before being uploaded in a database for analyses. Informed consent was obtained from all participants' parents. The schematic representation of the clinical audit cycle is shown in Figure 1.

Anthropometric measures

Page 2/6 
Body weight and height were measured in each pediatric office by the same pediatrician, who was specifically trained in anthropometry, according to standard procedures [15]. Body weight was determined to the nearest $0.1 \mathrm{~kg}$ on standard physician's beam scales (SECA 756, UK), with the subject wearing only underwear and no shoes. Height was measured to the nearest $0.1 \mathrm{~cm}$ using a stadiometer (SECA 213, UK). Measures of height were taken three times and the mean value was considered for data analysis. The body mass index (BMI) $\left(\mathrm{kg} / \mathrm{m}^{2}\right)$ was calculated as body weight divided by the square of height. Categories of normal weight (NW), overweight (OW) and obesity (OB) were defined according to the BMI thresholds proposed by the Centers for Disease Control and Prevention [16].

\section{Statistical analyses}

All statistical analyses were carried out using the Statistical Package of Social Sciences (SPSS, Chicago, IL, USA) for Windows software program release 15.0. A p value $<0.05$ was considered statistically significant. Results are reported as mean and standard deviations or as absolute and relative frequencies. The relative risk (RR) and the number needed to treat (NNT) adjusted for confounders were calculated.

\section{Results}

Demographic and anthropometric data of the Pre-Audit and Post-Audit groups assessed at the age of 24-36 months are shown in Table 1. The prevalence of overweight and obesity in the entire cohort of the Post-Audit Group was lower than that found in the Pre-Audit Group ( $p<0.0001)$ (Fig. 2). Specifically, reductions of $60 \%$ in the rate of overweight and $44 \%$ in the rate of obesity were found in the Post-Audit Group. The RRs for overweight or obesity were 7.63 (Confidence interval 3.09-12.16) and 7.71 (Confidence interval 3.74-11.67), respectively in the Pre-Audit cohorts with respect to the Post-Audit cohorts. The NNT was 14 for overweight and 13 for obesity.

\section{Discussion}

Our results have shown that the clinical audit is an effective tool in identifying inaccuracies in medical procedures and helpful in revising them. Specifically, peculiar changes in the dietary advices were associated to reduction of the risk of overweight and obesity in children between 24 and 36 months of age, living in an Italian region with high prevalence of overweight and obesity. Following the nutritional advices, it was estimated that protein intake changed from more than $3.5 \mathrm{~g} / \mathrm{kg}$ to about $2 \mathrm{~g} / \mathrm{kg}$ from 13 to 36 months [8]. In Southern Italy, only $29.1 \%$ children are breastfed at the age of 12 months, while the majority is fed with cow milk, $250 \mathrm{~mL}$ twice a day. Therefore, the protein intake from milk is generally equal to $16.5 \mathrm{~g}$, which adds to other proteins provided from meats, fish and eggs. Although the amount of $2 \mathrm{~g} / \mathrm{kg}$ of proteins is still far from the recommended reference levels of nutrient and energy intake for the ltalian population (LARN) [17], it was preferred to avoid dramatic changes in the established family habits in order to obtain greater compliance. However, protein intake was far less than the value of $3.5 \mathrm{~g} / \mathrm{kg}$, which is deemed to be a risk factor for lipogenesis and fat mass gain in early life [8].

The choice to consider a single factor (protein excess) has proved to be effective, despite the NNT was still high; on the other hand, improving childhood eating habits is among the duties and responsibilities of primary care pediatricians, hence it doesn't represent a further burden in their practice [18]. This study had some limits, such as the low number of pediatricians involved, the choice of considering a single indicator (protein excess) despite the multifaceted aspects of the pathology and the lack of a parallel control group. Considering these limits, a new study has been designed on a larger sample of children, in whom the effects of the change in nutritional procedures will be compared to an appropriate control group, and the influence of the other determinants of excess weight gain in early childhood, such as birth weight, parental obesity and the family socioeconomic level will be considered. The strength of the study was the implementation of evidence based procedures in the primary care setting. The availability of electronic clinical data of children, followed in the pediatric primary care office setting, has enabled the clinical audit.

\section{Conclusions}

This study, notwithstanding its simplicity, clearly showed the possibilities of self-evaluation and assessment of the work done by clinical audit and the consequences of the adjustments, where necessary, of the healthcare procedures. It represents also a useful starting point to plan studies involving a larger number of practitioners and patients, in order to verify the effectiveness of interventions.

\section{Abbreviations}

BMI

Body mass index

NNT

Number needed to treat

RR

Relative risk.

\section{References}

1. Baker R. Clinical audit in primary health care: Towards Quality assurance. BMJ. 1995;310:413.

2. Hoelscher DM, Kirk S, Ritchie L, Cunningham-Sabo L. Position of the Academy of Nutrition and Dietetics: Interventions for the Prevention and Treatment of Pediatric Overweight and Obesity. J Acad Nutr Diet. 2013;113:1375-94. 
3. Basso D, Avolio M, Sabetta T, Longhi S, Marino M, De AG, et al. The italian situation of overweight and obesity in childhood: A problem with epidemic proportions in the world. Aten Primaria. 2013;45:74-5.

4. Istat. Ricerca e sviluppo in italia. Anni 2014-2016. Stat Rep. 2016;:1-10.

5. Pan L, Li R, Park S, Galuska DA, Sherry B, Freedman DS. A longitudinal analysis of sugar-sweetened beverage intake in infancy and obesity at 6 years. World Review of Nutrition and Dietetics. 2016.

6. Hoppe C, Mølgaard C, Juul A, Michaelsen KF. High intakes of skimmed milk, but not meat, increase serum IGF-I and IGFBP-3 in eight-year-old boys. Eur J Clin Nutr. 2004;58:1211-6.

7. Hoppe C, Mølgaard C, Vaag A, Barkholt V, Michaelsen KF. High intakes of milk, but not meat, increase s-insulin and insulin resistance in 8-year-old boys. Eur J Clin Nutr. 2005;59:393-8.

8. Hörnell A, Lagström H, Lande B, Thorsdottir I. Protein intake from 0 to 18 years of age and its relation to health: a systematic literature review for the 5th Nordic Nutrition Recommendations. Food Nutr Res. 2013;57:21083.

9. Rolland-Cachera MF, Akrout M, Péneau S. Nutrient intakes in early life and risk of obesity. Int J Environ Res Public Health. $2016 ; 13$.

10. Eriksson JG, Forsén T, Tuomilehto J, Osmond C, Barker DJP. Early adiposity rebound in childhood and risk of Type 2 diabetes in adult life. Diabetologia. 2003;46:190-4.

11. Tirosh A, Afek A, Rudich A, Percik R, Gordon B, Ayalon N, et al. Progression of normotensive adolescents to hypertensive adults: A study of 26980 teenagers. Hypertension. 2010;56:203-9.

12. Weber M, Grote V, Closa-Monasterolo R, Escribano J, Langhendries JP, Dain E, et al. Lower protein content in infant formula reduces BMI and obesity risk at school age: Follow-up of a randomized trial. Am J Clin Nutr. 2014;99:1041-51.

13. Ivers N, Jamtvedt G, Flottorp S, Young JM, Odgaard-Jensen J, French SD, et al. Audit and feedback: effects on professional practice and healthcare outcomes. Cochrane Database Syst Rev. 2012.

14. Oddy WH. Infant feeding and obesity risk in the child. Breastfeed Rev. 2012.

15. Gallo P, Cioffi L, Limauro R, Farris E, Bianco V, Sassi R, et al. SGA Children in Pediatric Primary Care: What Is the Best Choice, Large or Small? A 10-Year Prospective Longitudinal Study. Glob Pediatr Heal. 2016.

16. Kuczmarski RJ, Ogden CL, Guo SS, Grummer-Strawn LM, Flegal KM, Mei Z, et al. 2000 CDC growth charts for the United States: Methods and development. Nationale Center for Health Statistics. 2002.

17. SINU. Livelli di Assunzione di Riferimento di Nutrienti ed energia per la popolazione italiana. Sintesi prefinale. 2012;:22-3. http://scholar.google.com/scholar? $\mathrm{hl}=$ en\&btnG=Search\&q=intitle:Livelli+di+Assunzione+di+Riferimento+di+Nutrienti+ed+energia+per+la+popolazione+italiana\#0\%5Cnhttp://nut.entecra.it/6

18. Valerio G, Maffeis C, Saggese G, Ambruzzi MA, Balsamo A, Bellone S, et al. Diagnosis, treatment and prevention of pediatric obesity: Consensus position statement of the Italian Society for Pediatric Endocrinology and Diabetology and the Italian Society of Pediatrics. Italian Journal of Pediatrics. 2018.

\section{Declarations}

Ethics approval and consent to participate The study was approved by the Ethical Committee "Campania Sud" of the ASL Napoli 3 Sud. Informed consent was obtained from all participants' parents.

\section{Consent for publication}

Not applicable.

\section{Availability of data and materials}

Datasets used and/or analyzed during the current study are available from the corresponding author on reasonable request.

\section{Competing interests}

The authors declare that they have no competing interests.

\section{Funding}

No funding was received for the preparation of this paper. 
$\mathrm{RL}$ contributed to the conception and design of the study, to the acquisition, analysis and interpretation of the data, and drafted and completed the manuscript. PG contributed to the conception and design of the study, to the acquisition and interpretation of data and revised the manuscript. LC contributed to the conception and design of the study, to acquisition, analysis and interpretation of the data, and revised the manuscript. AA and VC revised the manuscript. PC drafted and revised the manuscript. GV contributed to interpretation of the data, drafted and completed the manuscript. All authors read and approved the final manuscript.

\section{Acknowledgements}

Not applicable.

\section{Tables}

Table 1. Demographic and anthropometric data of children included in the Pre-Audit and in the Post-Audit groups at the age of 24-36 months.

\begin{tabular}{|c|c|c|c|c|c|c|}
\hline & \multicolumn{3}{|c|}{$\begin{array}{c}\text { Pre-audit group } \\
\text { Birth year }\end{array}$} & \multicolumn{3}{c|}{$\begin{array}{c}\text { Post-audit group } \\
\text { Birth year }\end{array}$} \\
\hline & $\mathbf{2 0 0 5}$ & $\mathbf{2 0 0 6}$ & $\mathbf{2 0 0 7}$ & $\mathbf{2 0 1 0}$ & $\mathbf{2 0 1 1}$ & $\mathbf{2 0 1 2}$ \\
\hline Number & 135 & 136 & 196 & 155 & 146 & 165 \\
\hline Boys/girls & $71 / 64$ & $66 / 70$ & $104 / 92$ & $78 / 77$ & $70 / 76$ & $87 / 78$ \\
\hline Age (months) & $30.7 \pm 2.0$ & $30.7 \pm 2.9$ & $31.7 \pm 3.4$ & $30.7 \pm 3.2$ & $29.2 \pm 3.1$ & $30.2 \pm 2.6$ \\
\hline Weight (kg) & $14.3 \pm 2.4$ & $14.3 \pm 2.3$ & $14.5 \pm 1.8$ & $14.1 \pm 1.9$ & $13.6 \pm 1.8$ & $13.8 \pm 1.6$ \\
\hline Length/height (cm) & $91.1 \pm 9.2$ & $92.3 \pm 4.1$ & $92.8 \pm 4.1$ & $91.9 \pm 3.8$ & $90.8 \pm 3.1$ & $91.3 \pm 3.7$ \\
\hline BMI & $16.6 \pm 2.2$ & $16.8 \pm 1.5$ & $16.7 \pm 1.7$ & $16.6 \pm 3.3$ & $16.4 \pm 1.3$ & $16.3 \pm 1.5$ \\
\hline Normal weight n (\%) & $96(71.1)$ & $108(79.3)$ & $140(71.4)$ & $130(83.9)$ & $129(88.3)$ & $142(85.7)$ \\
\hline Overweight n (\%) & $20(14.8)$ & $18(13.2)$ & $33(16.8)$ & $11(7.1)$ & $11(7.5)$ & $20(10.2)$ \\
\hline Obesity n (\%) & $19(14.1)$ & $10(7.4)$ & $23(11.8)$ & $14(9.0)$ & $6(4.1)$ & $3(4.0)$ \\
\hline
\end{tabular}

Table 2. Feeding recommendations from 6 to 36 months in the Pre- and Post-Audit periods.

\begin{tabular}{|l|l|}
\hline \multicolumn{1}{|c|}{ Pre-Audit period } & \multicolumn{1}{|c|}{ Post-Audit period } \\
\hline Row meat or fish 30 gr per meal from weaning to 12 months & Row meat or fish 15 gr per meal from weaning to 12 months \\
\hline $\begin{array}{l}\text { No information that legumes and parmesan are protein source and } \\
\text { excellent substitutes of meat and fish }\end{array}$ & $\begin{array}{l}\text { Advise to alternate both vegetal and animal food proteins } \\
\text { (legumes 3-4 times/week; fish 3-4 times/week) }\end{array}$ \\
\hline $\begin{array}{l}\text { Breast milk until 24 months or cow milk after the age of 12 months } \\
\text { (protein content roughly 3.3 gr/100 ml)* }\end{array}$ & $\begin{array}{l}\text { Breast milk until 24 months or formula until 36 months of } \\
\text { age (protein content roughly 1.4-1.6 gr/100 ml) }\end{array}$ \\
\hline $\begin{array}{l}\text { No information that the second course (commercial or fresh baby } \\
\text { food) needs to be weighted after the age of 12 months }\end{array}$ & $\begin{array}{l}\text { Commercial baby food } 80 \mathrm{gr} \text { or 30 gr row meat or fish per } \\
\text { meal after the age of 12 months }\end{array}$ \\
\hline No specific advice to avoid sugar excess & $\begin{array}{l}\text { Specific advice to avoid food high in sugar and sugar- } \\
\text { sweetened beverages }\end{array}$ \\
\hline
\end{tabular}

*In Southern Italy only 29,1\% of children receive breast milk at the age of 12 months (Italian National Institute of Statistics, ISTAT 2015)

\section{Figures}




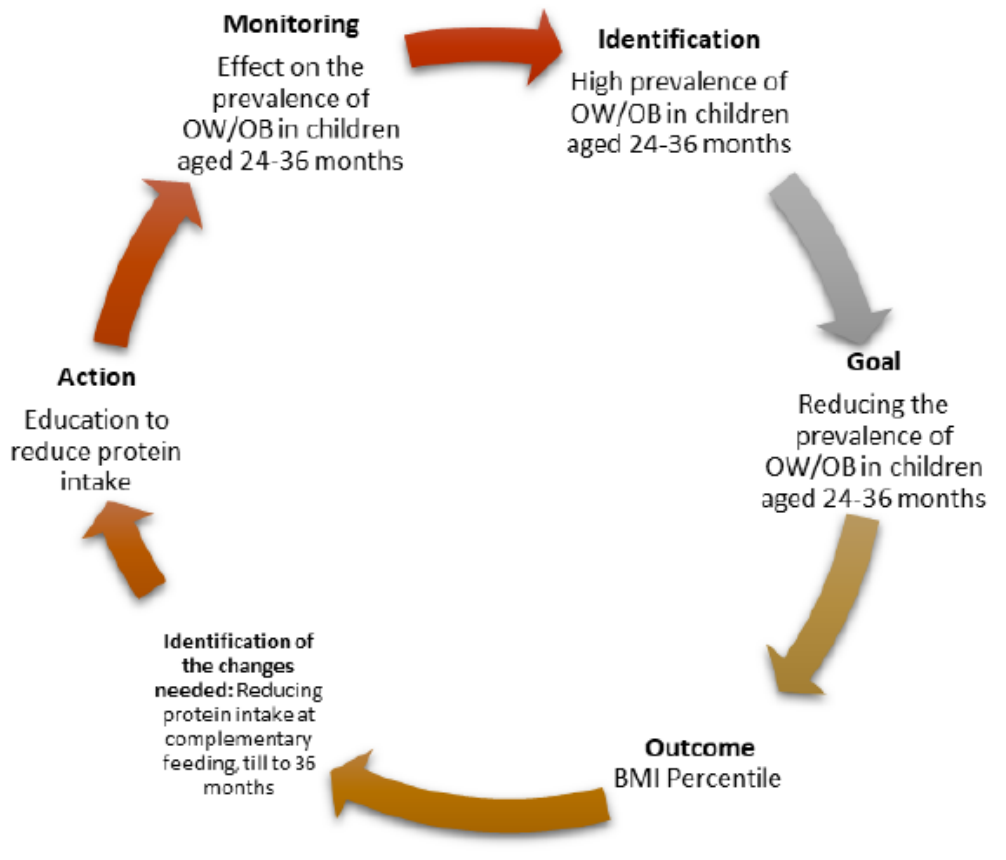

Figure 1

The schematic representation of the clinical audit cycle.

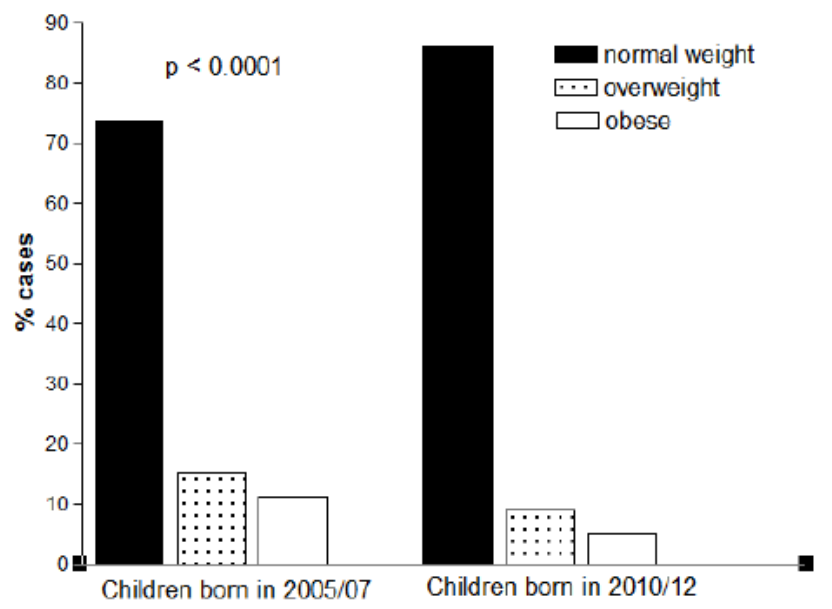

Figure 2

Prevalence of normal-weight, overweight and obesity in the entire cohort of children aged 24-36 months in the Pre-Audit and Post-Audit groups. 